\title{
Implementing and Evaluating the Bridges Stroke Self- Management Programme into a New Zealand District Health Board Stroke Service: A Case Study
}

Leigh Hale $P h D$

Professor and Dean, Centre for Health, Activity and Rehabilitation Research, School of Physiotherapy, University of Otago, Dunedin, New Zealand

Mandy McCulloch DPT

Professional Practice Fellow, School of Physiotherapy, University of Otago, Dunedin, New Zealand

Samuel De Ruiter* BPhty

School of Physiotherapy, University of Otago, Dunedin, New Zealand

Evelyn Wihongia* BPhty

School of Physiotherapy, University of Otago, Dunedin, New Zealand

Erina Mcdonnell Norlinga* BPhty

School of Physiotherapy, University of Otago, Dunedin, New Zealand

Daniel Gorczynski* BPhty

School of Physiotherapy, University of Otago, Dunedin, New Zealand

Michael Linney* BPhty

School of Physiotherapy, University of Otago, Dunedin, New Zealand

Paden Kennedy* BPhty

School of Physiotherapy, University of Otago, Dunedin, New Zealand

Fiona Jones $P h D$

Professor of Rehabilitation Research, Faculty of Health, Social Care and Education, St George's, University of London, London, United Kingdom

*Bachelor of Physiotherapy students at the time this research was conducted.

\section{ABSTRACT}

The impact of stroke is lifelong; affecting independence and quality of life. Stroke survivors need support to manage their recovery. The Bridges stroke self-management approach (Bridges) empowers stroke survivors and facilitates self-management within usual rehabilitation. We implemented Bridges into a New Zealand stroke service, aiming to identify context-specific delivery factors and long-term sustainability strategies. Using a case study design, data were collected from multiple sources, including meeting and training notes, researcher observations, workshop evaluations, and in-depth semi-structured interviews $(n=7)$. Data were compared for congruency or disparity, and integrated to develop a comprehensive case description. Overall, 69 health professionals were trained. Collectively, the data found Bridges to be conceptually acceptable and contextually appropriate, raising awareness of self-management support across the service. Identified key factors that would assist with the implementation of this new intervention, including the need for time and sustained support for staff; an initial small, contained inter-professional team; ongoing communication to staff by managers about their expectations and endorsement of the intervention; and staff "champions", requiring training, resources, and managerial support. Whilst staff may value Bridges, they needed time and the opportunity to develop knowledge, skills, and self-efficacy to support patient self-management.

Hale, L., McCulloch, M., De Ruiter, S., Wihongia, E., Mcdonnell Norlinga, E., Gorczynski, D., Linney, M., Kennedy, P., \& Jones, F. (2021). Implementing and evaluating the Bridges stroke self-management programme into a New Zealand district health board stroke service: A case study. New Zealand Journal of Physiotherapy, 49(2), 58-69. https://doi. org/10.15619/NZJP/49.2.02

Key Words: Health Plan Implementation, Health Services, Self-Efficacy, Self-Management, Stroke, Stroke Rehabilitation

\section{INTRODUCTION}

In New Zealand about 50,000 people live with disability caused by stroke (Ranta, 2018) Although recovery from stroke can continue throughout life, little long-term rehabilitation is provided nationally for stroke survivors (Brown, 2009; Hogan \& Siddharth, 2018). In New Zealand and elsewhere, 
stroke survivors commonly express feelings of isolation and abandonment after discharge, and high levels of unmet clinical and social needs (Hogan \& Siddharth, 2018; McKevitt et al., 2011; Pindus et al., 2018).

Stroke can be conceptualised as a long-term condition as there is a life-long impact on independence and quality of life (Jones, 2006; Fryer et al., 2016; O'Neill et al., 2008). Supporting self-management in stroke rehabilitation can improve quality of life and reduce dependency on others (Fryer et al., 2016). Self-management support has been defined as including "all the actions taken by people to recognise, treat and manage their own healthcare independently of or in partnership with the healthcare system" (The Evidence Centre for National Voices, 2014, p.3). As coping post-stroke can be extremely difficult and present complex challenges, such as low mood, or communication and mobility dysfunction, many people need to develop new skills and knowledge for self-management (Jones, 2006). Approaches using healthcare interactions within usual care to coach or support patient self-management skill development are proven to be beneficial and potentially costeffective (De Silva, 2011; Jones \& Brimicombe, 2014). Such approaches foster self-management skills from the outset, improve patient self-confidence, and avoid possible "learnt" dependency on health professionals. Early integration of selfmanagement support for patients could reduce the sense of abandonment after discharge and enhance their ability to cope (Fryer et al., 2016; Newbronner et al., 2013).

In the Bridges stroke self-management approach (Bridges), health professionals are trained to support stroke survivors within usual rehabilitation interactions to develop the skills and confidence to take control of their own rehabilitation and recovery (Jones et al., 2009, 2015; McKenna, Jones, et al., 2015). A workbook, owned and completed by the stroke survivor, is a tool to facilitate this process. Patients are supported to reflect on their achievements, and attribute positive changes in their functioning and well-being to their own efforts, rather than to the skills and expertise of a healthcare practitioner (Jones et al., 2009, 2015; McKenna, Jones, et al., 2015). There is evidence that Bridges positively impacts functional activity, social integration, and quality of life (Jones et al., 2015), and has demonstrated feasibility of delivery and acceptability to patients, carers, and professionals in a variety of healthcare settings (Jones et al., 2015, 2016, 2017; Kulnik et al., 2016; McKenna, Martin, et al., 2015).

We believe Bridges has potential to support New Zealand stroke survivors in their recovery. Implementation of a new intervention, particularly at an organisational level, such as a stroke service, requires those impacted to embrace the intervention, and feel prepared, committed and confident in their collective ability to change practices (Moir, 2018). Implementation thus necessitates a systematic approach (Peters et al., 2013; Powell et al., 2019), acknowledging the importance of addressing key contextual determinants (Peters et al., 2013; Powell et al., 2019). This approach, developed in the United Kingdom, may not be acceptable or suitable in a New Zealand context. Our first study contextualised Bridges and its accompanying workbook for New Zealand, and established its relevancy and acceptability to both stroke survivors and stroke rehabilitation practitioners (Hale et al., 2014).
In this study, we aimed to further our understanding of the acceptability and potential for adoption of Bridges within the New Zealand context. We implemented Bridges into the stroke care pathway of a small New Zealand district health board (DHB) and evaluated implementation in terms of acceptability and adoption (Peters et al., 2013). The DHB's clinical board was supportive and had an expectation that self-management support would become an integral component of their healthcare service. Specifically, our objective was to identify (a) context-specific delivery factors, (b) sustainability strategies, and (c) staff perceptions of Bridges.

\section{METHODS}

\section{Study design}

We employed a mixed-method case study design to investigate a contemporary phenomenon within its real-world context (Yin, 2014). Case studies draw on multiple data sources to inform the research aims. Ethical approval was obtained from the Health and Disability Ethics Committee, New Zealand (reference 18/ STH/93)

\section{Setting}

The study DHB serves a population of 60,000 (20\% are older adults, about 900 are stroke survivors) and has about 100 stroke admissions per year (Ranta, 2018). Using a multidisciplinary approach, the stroke pathway begins with admission via the emergency department into the medical ward or the intensive care unit of the city hospital. Within two hours to four days, stroke survivors are transferred to the assessment, treatment and rehabilitation (AT\&R) unit for a duration of at least 7 days. The integrative community assessment treatment team assists stroke survivors with a discharge plan, and the person is referred, as appropriate, to community organisations, such as the Stroke Foundation, a community stroke advisor, or the "Home First" service (a 6-week support and rehabilitation service in the person's home). Overall care is coordinated by the stroke clinical nurse specialist.

\section{Implementing Bridges into the DHB stroke service} We used Normalisation Process Theory to guide a systematic and planned delivery of Bridges, as it provides a framework to assess facilitators and barriers to the integration of complex interventions into routine practice (Murray et al., 2010). This theory comprises four constructs that interact with the organisational culture and processes (Murray et al., 2010):

1. Coherence: We first illustrated to staff and management the differences between Bridges and current practice. We met with senior and middle managers, and staff over several months to gain an understanding of the DHB and its stroke services, and to raise awareness of Bridges, its aims and benefits.

2. Cognitive participation: Together with staff and management, we identified appropriate methods for incorporating Bridges into the DHB's ways of working, for example, which staff to involve, when and how to deliver training, and how to contextually adapt training relevancy (e.g., background context, culture, employment, rural and city dwelling), journey of stroke survivors through the services, and staff they will typically see. 
3. Collective action: Through collaborative discussions and action planning, we contextualised training workshop material and identified strategies (e.g., drop-in lunchtime support sessions via videoconferencing) to support staff.

4. Reflexive monitoring: We reflected with staff to understand progress and thereby identified strategies to enable sustainability.

Training, which has been described by Jones \& Bailey (2013), was delivered in two stages by two Bridges associate trainers, with a full-day initial workshop (June 2018) and half-day follow-up workshop 4 months later (November 2018). Due to shiftwork, many nurses could not attend the workshops, and an abbreviated 2-hr workshop was designed and delivered to ward nurses in line with previous Bridges training (Mäkelä et al., 2014). Prior to training, attendees experiences and perceptions about self-management support were explored; these findings have been reported previously (Taylor et al., 2019).

Between workshops, the Bridges trainers supported staff to implement Bridges with fortnightly newsletters and posters, email reminders, lunchtime videoconferencing sessions, and a face-to-face problem-solving workshop. In these sessions, trainers facilitated staff to problem solve challenges they were encountering (e.g., the speech and language therapist requested advice on how to adapt Bridges for her communitybased communications group). Halfway through this period, one trainer (LH) spent time observing the practice of consenting staff on the wards and the community-based communications group, as a peer review exercise. Observations were noted on a Bridges study checklist, and staff provided feedback (McKenna, Martin, et al., 2015).

Data collection

Eligibility and recruitment

Multidisciplinary staff involved in the stroke service were requested by management to attend the training, and all were eligible for inclusion into the evaluative part of our project. Prior to training, we sent staff study information sheets and consent forms via email. Those staff wishing to be part of the evaluation stage provided us with a signed consent form. Staff chose the extent to which they wished to be involved in the evaluation and were reassured of anonymity. To further ensure confidentiality, one-on-one interviews (as opposed to focus groups) were undertaken to collect data.

Data sources

A range of data sources were used in the study:

1. Notes from meetings and observations made by research team members.

2. Training workshops evaluations completed during the two training workshops (Mäkelä et al., 2014).

3. A record of ideas from attendees of how they thought Bridges could be sustained in the service. This was requested from attendees in the second training workshop.

4. Qualitative semi-structured, in-depth interviews undertaken 2-3 months following the second training workshop with consenting staff, facilitated by one researcher (MMcC).
Topics explored included feasibility and acceptability, benefits and limitations, delivery improvement, and sustainability. Interviews took place at a venue acceptable to the interviewees (to preserve anonymity), and were audiorecorded and transcribed in full by a commercial transcribing firm (instructed to ensure anonymity of participants and organisations).

\section{Data analysis}

Workshop evaluation data from closed questions were analysed descriptively (medians, ranges), and open-ended question responses were thematically analysed. Interview data were analysed guided by the General Inductive Approach (Thomas, 2016). In this process, the transcripts were individually and independently coded by six researchers (SDR, EW, EMcN, DG, $\mathrm{ML}, \mathrm{PK}$ ) without discussion, and then discussed by all, collated, and collapsed into four draft themes. These six researchers then recoded the transcripts with the draft themes, which, with further debate, were refined and an agreement on three finalised themes reached. Transcripts were recoded using the finalised themes, and a peer review of these codes and themes was completed by switching transcripts amongst the researchers and the primary author (LH). Other data collected (minutes, recorded observations, second workshop data) were read multiple times by the primary author, thematically coded, and collated. In keeping with the case study design, all analysed data were compared for congruency and disparity, and integrated to develop a comprehensive description of the case and address study objectives. Integrated data from all sources were discussed between the primary author and a researcher (MMcC) at three meetings to reach consensus, and verified with the DHB staff at a post-study presentation and feedback workshop.

\section{RESULTS}

In this section we present the data collected from each source.

\section{Notes of meetings and observations}

In our initial consultation with senior and middle management, the consensus was to adopt a targeted approach for implementing Bridges focussing on stroke and training all staff involved in the DHB's stroke care pathway, from acute to community. Thus, at the initial training workshop, 51 staff were trained (22 nurses, eight physiotherapists, eight occupational therapists, five social workers, two dietitions, one occupational therapy assistant, one speech-language therapist, one hospital liaison officer, two physiotherapy assistants, and one community stroke advisor). We did this over three full days, each member of staff attending one full day. At this point, the senior manager was able to fully engage and ensure staff attended, reimbursing those staff attending in their off-duty time. Unfortunately, restructuring of the DHB at a senior management level resulted in the senior manager taking on more duties, leaving less time to devote to the Bridges training. Additionally, following the first workshop, the staff turnover was high: five occupational therapists and one speech language therapist left the service. Thus, attendance at the second workshop was low, with only 12 attending. 


\section{Workshop evaluations}

Table 1 presents the results of the two training workshop evaluations. These data show that participants considered the training relevant to their individual and service/team practices, they had high confidence and intention to use Bridges, and all but one participant would recommend the workshop to others. The themed responses to the open-ended questions are shown in Table 2 (initial training workshop) and Table 3 (second training workshop).
Second training workshop data

When workshop attendees were asked how Bridges could be sustained within their service, the main suggestions were refresher courses and new staff training resources, as shown in Table 4.

\section{In-depth qualitative interviews}

At the time of the first training workshop, 24 of the 51

attendees consented to be interviewed. However, subsequent to

\section{Table 1}

Evaluation of First and Second Workshops

\begin{tabular}{|c|c|c|c|c|}
\hline \multirow{2}{*}{ Questions } & \multicolumn{2}{|c|}{ First workshop $(n=48 / 51)$} & \multicolumn{2}{|c|}{ Second workshop $(n=12 / 12)$} \\
\hline & Median & Range & Median & Range \\
\hline $\begin{array}{l}\text { Rate training in terms of relevance to your role. } \\
\qquad(1-4: \text { : not at all" to "very" relevant) }\end{array}$ & 3 & $2-4$ & 4 & $3-4$ \\
\hline $\begin{array}{l}\text { Rate the training in terms of relevance to your team/service. } \\
\qquad(1-4: \text { "not at all" to "very" relevant) }\end{array}$ & 4 & $2-4$ & 4 & $3-4$ \\
\hline $\begin{array}{l}\text { How confident do you feel right now to use Bridges in your } \\
\text { practice? } \\
\quad(1-8: \text { "not" to "very" confident) }\end{array}$ & 7 & $4-10$ & 8 & $5-10$ \\
\hline $\begin{array}{l}\text { What is your intention to use Bridges in your role after today? } \\
\qquad(1-10: \text { "no" to "every" intention) }\end{array}$ & 8 & $4-10$ & 8.5 & $4-10$ \\
\hline $\begin{array}{l}\text { How confident do you feel right now, to explain the concept of } \\
\text { Bridges and self-management support to colleagues who were } \\
\text { not at the training today? } \\
\quad(1-10: \text { " not" to "very" confident) }\end{array}$ & 7 & $3-9$ & 8.5 & $5-10$ \\
\hline Do you feel that the workshop will enhance your practice? & $\begin{array}{l}\text { Yes }=44 \\
\text { No }=1\end{array}$ & $\begin{array}{l}\text { Maybe }=2 \\
\text { DNA }=1\end{array}$ & $\begin{array}{c}\text { Yes }=11 \\
\text { No }=1\end{array}$ & \\
\hline Would you recommend this workshop to a colleague? & $\begin{array}{c}\text { Yes }=47 \\
\text { No }=1\end{array}$ & & & \\
\hline
\end{tabular}

Note. DNA = did not attend.

\section{Table 2}

First Workshop Attendee Perspectives of Impact on Their Practice and Foreseeable Barriers to Implementation of Bridges ( $\mathrm{N}=51)$

How might the workshop enhance your practice? What barriers do you forsee in implementing Bridges into practice?

\begin{tabular}{|c|c|c|c|}
\hline Theme & Illustrative quotes & Theme & Illustrative quotes \\
\hline $\begin{array}{l}\text { Confidence to } \\
\text { empower a } \\
\text { patient to self- } \\
\text { management }\end{array}$ & $\begin{array}{l}\text { "Provided clarity to ensure } \\
\text { I allow patients to self } \\
\text { manage, increased my } \\
\text { awareness of how I ask } \\
\text { questions, what I ask } \\
\text { and how I influence a } \\
\text { patient's self-efficacy } \\
\text { and ability to manage } \\
\text { self." } \\
\text { "I'll be more confident to } \\
\text { step back and encourage } \\
\text { family and PT self- } \\
\text { management." }\end{array}$ & $\begin{array}{l}\text { Consistency and } \\
\text { sustainability }\end{array}$ & $\begin{array}{l}\text { "Not all staff on ward and in community have been } \\
\text { trained." } \\
\text { "Not all staff encouraging/educating patients to use } \\
\text { this." } \\
\text { "How will consistency, sustainability, and measuring } \\
\text { progress be managed?" } \\
\text { "Slipping back into "business as usual " rather than } \\
\text { continuing the change." }\end{array}$ \\
\hline
\end{tabular}




\begin{tabular}{|c|c|c|c|}
\hline \multicolumn{2}{|c|}{ How might the workshop enhance your practice? } & \multicolumn{2}{|c|}{ What barriers do you forsee in implementing Bridges into practice? } \\
\hline Theme & Illustrative quotes & Theme & Illustrative quotes \\
\hline $\begin{array}{l}\text { Improved } \\
\text { communication }\end{array}$ & $\begin{array}{l}\text { "Improve communication } \\
\text { and relationship with } \\
\text { person and family." } \\
\text { "The use of different } \\
\text { words to help clients, } \\
\text { allowing more honest/ } \\
\text { direct/relevant } \\
\text { communication } \\
\text { pathways to develop } \\
\text { between myself and my } \\
\text { clients." }\end{array}$ & $\begin{array}{l}\text { Patients with } \\
\text { cognitive } \\
\text { impairments, } \\
\text { aphasia or living } \\
\text { alone }\end{array}$ & $\begin{array}{l}\text { "Difficult for those with no family/friends. (I have many } \\
\text { isolated older adults with aphasia living alone at } \\
\text { home)." } \\
\text { "In my area - advanced age/cognition decline/ } \\
\text { multiple medical comorbidities/individual and family } \\
\text { expectations on the healthcare system." }\end{array}$ \\
\hline $\begin{array}{l}\text { What we do in } \\
\text { practice already }\end{array}$ & $\begin{array}{l}\text { "Already enforces what } \\
\text { we as occupational } \\
\text { therapists do." } \\
\text { "It reaffirms my solution- } \\
\text { focused practise, but } \\
\text { I need to listen to the } \\
\text { client to write a goal that } \\
\text { they will own." } \\
\text { "A lot of these techniques } \\
\text { are really social work." }\end{array}$ & $\begin{array}{l}\text { Clients not wishing } \\
\text { to self-manage }\end{array}$ & $\begin{array}{l}\text { "Clients dependent on outside/formal assistance and } \\
\text { how it benefits their lives." } \\
\text { "Age of our clients - maybe resistant to change and/or } \\
\text { self motivation." } \\
\text { "Needs Assessment and Service Coordination service } \\
\text { is a needs not want/wish, service - already have a } \\
\text { restorative approach - how will we "unlearn" this?" } \\
\text { "Patient expectations of a cure, forgetting they are } \\
\text { ageing." } \\
\text { "Patients wanting to be 'done to'." }\end{array}$ \\
\hline New skills and ideas & $\begin{array}{l}\text { "Looking at a patient in a } \\
\text { different way." } \\
\text { "Self reflection on how I } \\
\text { interact and try to be less } \\
\text { didactic." } \\
\text { "To promote self-reflection } \\
\text { of clients who are poorly } \\
\text { motivated." }\end{array}$ & $\begin{array}{l}\text { Finding suitable } \\
\text { clients }\end{array}$ & $\begin{array}{l}\text { "Not working much with patients with stroke." } \\
\text { "A long-term condition approach would be better." } \\
\text { "Low number of patients with stroke - but the } \\
\text { principles can be used with patients with long-term } \\
\text { conditions." } \\
\text { "Personal beliefs about this programme - not all } \\
\text { engaged in the philosophy." } \\
\text { "Change resistance - afraid of change." } \\
\text { "Staff lack of motivation." } \\
\text { "Staff inflexibility in their practice." } \\
\text { "Limited time for staff." } \\
\text { "Time constraints and pressure on staffing. " }\end{array}$ \\
\hline
\end{tabular}

\section{Table 3}

Second Workshop Attendee Perspectives of Impact on Their Practice and Foreseeable Barriers to Implementation of Bridges $(\mathrm{N}=12)$

How might the workshop enhance your practice?

Theme

"Focusing on what the patient wants instead of what
the health practitioner wants. If we have goals for
patients, they are less likely to achieve them. If they
have their own goals, they are more likely to achieve
them and achieve them faster."
"Changing roles with successful collaborative working
of multidisciplinary team during patient journey to
empower patient. Giving patient and families belief
to change or adopt to manage/change new health
status."

What barriers do you foresee in implementing Bridges into practice?
Resistance to change Theme

Illustrative quote

"That the team will not take it on. Only a few will do it."

"Staff reluctance for change."

"Personal beliefs from healthcare profession cultural background." 


\begin{tabular}{|c|c|c|c|}
\hline Theme & Illustrative quote & Theme & Illustrative quote \\
\hline & $\begin{array}{l}\text { "Working on the things that are meaningful for the } \\
\text { patient. Not wasting time on things they are not } \\
\text { focussed on." } \\
\text { "Supporting patients to think about what they want to } \\
\text { achieve." } \\
\text { "Workshop also highlighted not to dismiss this } \\
\text { approach for patients who might have cognitive/ } \\
\text { communication difficulties." } \\
\text { "Decrease reliance on health professsionals in the long } \\
\text { term. Improve patient confidence." } \\
\text { "Ensure care is meaningful to patient. Highlighting } \\
\text { importance of identifying and recognising goals/ } \\
\text { meaningful activities for patients." }\end{array}$ & & \\
\hline $\begin{array}{l}\text { Insightful but } \\
\text { difficult to } \\
\text { achieve }\end{array}$ & $\begin{array}{l}\text { "Given me insight into approaching rehab from a } \\
\text { different perspective. For me, this is a work in } \\
\text { progress. This is more difficult for me to achieve as I } \\
\text { am an assistant, not a registered health professional." }\end{array}$ & Sustainability & $\begin{array}{l}\text { "Sustainability, i.e., people } \\
\text { who have been trained } \\
\text { leaving their jobs." } \\
\text { "Training for new staff." } \\
\text { "Slipping back into old } \\
\text { ways." } \\
\text { "Return to practice as } \\
\text { normal with time } \\
\text { pressures." } \\
\text { "Losing others who have } \\
\text { trained and who can } \\
\text { offer support." }\end{array}$ \\
\hline $\begin{array}{l}\text { This is what we do } \\
\text { anyway }\end{array}$ & $\begin{array}{l}\text { "Reinforcement of social work practice." } \\
\text { "Reinforced my practice." }\end{array}$ & Constant change & $\begin{array}{l}\text { "I think that as a hospital, } \\
\text { lots of different things } \\
\text { have been tried in other } \\
\text { countries then brought } \\
\text { here, possibly we are all } \\
\text { tired of new concepts. " }\end{array}$ \\
\hline $\begin{array}{l}\text { Enhanced skills to } \\
\text { support self- } \\
\text { management }\end{array}$ & $\begin{array}{l}\text { "Bridges helped me to encourage self-management for } \\
\text { our patients. It takes time but improves outcomes for } \\
\text { patients, helped me focus on the patient's goals." } \\
\text { "The use of empowerment." } \\
\text { "Focus on patients' strengths." } \\
\text { "Using strategies of self-management with patients. } \\
\text { Allowing patients to self reflect on own capabilities." } \\
\text { "Promote ability to really know what is important to the } \\
\text { person. Identify those who would be able to achieve } \\
\text { this with less versus more input and keeping people } \\
\text { enagaged and motivated on things they love." }\end{array}$ & $\begin{array}{l}\text { Strong influence } \\
\text { of the medical } \\
\text { model of } \\
\text { healthcare }\end{array}$ & $\begin{array}{l}\text { "Overall "medical model" } \\
\text { of hospital and of initial } \\
\text { training." }\end{array}$ \\
\hline
\end{tabular}

the second workshop, only seven participants (five females and two males) were available: two physiotherapists, one dietitian, one occupational therapist, one manager, one social worker, and one nurse. Data analysis identified three key themes: valued but we do this anyway, barriers to implementation, and sustainability. Each theme, with relevant supporting quotes, is described below (names are pseudonyms).
Valued but we do this anyway

All participants emphasised they valued the Bridges concepts and spoke of how the language in the DHB had changed since the training to reflect that of self-management. Mary (physiotherapist): "So many of the conversations I have had [commenting on the impact of the initial training on staff], it comes down to two words - communication and language". 


\section{Table 4}

Second Training Workshop Attendee Feedback $(N=12)$

Ideas for sustainability

Orientation package for new staff: ... "We use the Bridges approach to self-management - this is what it means ..."

Annual $2 \mathrm{hr}$ refresher training

Training resources on the HealthLearn forum

Resources to include videos and stories

Some staff become trained as Bridges trainers

Need staff champions to drive Bridges

Mandatory peer review

Change language used in team meetings

Change goal-setting process

Patients' goals should be visible to all, so all can assist in their achievement - perhaps a "goal book" at end of bed

For non-stroke patients, a goal-setting/reflection book (staff were only provided with the Bridges workbook to give to patients)

Working more as a team

Change culture of the ward

Discussion in relation to other programmes within the service and their interaction with Bridges, e.g., falls prevention, the Calderdale framework

Rose (manager) elaborated: "The highlight is seeing that change of mindset for those professionals ... it's certainly highlighted to our community workforce around the importance of self-management". Participants spoke of how their practice changed, for example, John (charge nurse):

I am more aware now than I used to be, we have always tried to encourage people to be independent, but then, the training helped me with the use of my words, how to encourage the patients to self-manage and to be independent and try to problem solve.

Mary (physiotherapist) spoke of how the approach was feasible even for those with aphasia: "The speech and language therapist took it to her communication group and created an incredible amount of excitement there."

However some participants felt they already employed these techniques in their practice, as described by Lucy (social worker): "I think the whole is a really good idea, I guess for social workers a lot of it is stuff that we are doing anyway, so it's not new to us." Sophie (dietitian) reiterated this point: "I didn't feel like I changed too much with my practice." Sophie also went on to report that some staff attending the initial workshop had struggled to see the relevance of Bridges to their practice: "In the training, not everyone was on board either, like you could see that lots of people were, 'Why am I here, I'm losing a day', you know, I'm already doing this with my patients." Rose (manager) agreed that some staff did not link the new theory learnt to their current practice:

People didn't feel that they were treating stroke patients so there was that disconnect ... some people didn't see the benefit of what we were trying to sell in the sense of the self-management principles they can use for any long-term condition.

\section{Barriers to implementation}

Several barriers to implementation were identified, namely limited numbers of patients with stroke, Bridges differing to usual professional training, conflicting concepts from other programmes, a task-orientated hospital culture, resistance to change, and that the approach takes more time.

Some participants said they were unable to implement Bridges due to a lack of opportunity in the area they worked in, for example Lucy (social worker) stated: "Unfortunately I don't get an opportunity to use it and I won't in palliative care either." Becky (occupational therapist) agreed: "We've got such small numbers of stroke patients coming through ... we would need to move it on to other long-term conditions too."

Sophie (dietitian) talked about how Bridges differed from how they were trained: "We all get trained in a more, medical model rather than a patient-centred model." This concern extended to their role as a professional in a particular field, particularly for novice practitioners, as Mary (physiotherapist) pointed out: "Some people struggled with the concept because they were still establishing themselves in their professional roles and the identity that gave them, and were still working on their own skills and knowledge."

Participants felt that other programmes run at the same time as Bridges potentially caused conflict. Concern was expressed at how enabling patients to set their own goals could be risky, for example, if the patient chose a goal of walking without their stick and chose to do this whilst they were still considered a falls risk, an example of how Bridges was perceived to conflict with the current falls prevention programme. These thoughts are clearly described by Becky (occupational therapist): "We run a falls prevention programme and we're running Bridges and we know that as we allow patients to test their boundaries, which programme comes first? Are there going to be consequences [for them as health professionals]?"

Participants spoke about how their usual practice was task orientated, and this was unhelpful for promoting patient self-management, as described by Becky (occupational therapist): "The culture in AT\&R, as much as it's supposed to be 
rehabilitation, there's still that ... underlying culture of being task orientated, so everyone has to have a shower today, even if they only shower once a week at home."

Participants perceived that including Bridges into their practice would be time consuming, especially if concurrently implementing other new interventions. Becky (occupational therapist) stated: "It gets quite difficult when you are implementing a new model ... trying to be done on top of everything else and all the competing agendas." And as Lucy (dietitian) pointed out: "There's too much ... we can't remember it all, and something else comes along, and we forget about the last thing." Additionally, participants spoke of the reluctance of some staff to change their practice, as articulated by Rose (manager): "That's what you get [with] any kind of change that you're trying to make, you always have that small group that you know, sort of question what you're doing and why you're doing it."

The scope of staff trained was considered too broad, and that a more narrowly targeted training programme would have increased the use of Bridges, for example, training only staff from the AT\&R ward. Additionally, some thought that the implementation of Bridges should have extended beyond stroke to include other long-term conditions, as stated by Sophie: "I think that it's a focus that should be with everything not just stroke."

\section{Sustainability}

Sustainability of the approach was considered important by study participants. Continued training and support, on top of the initial training, for example, as part of an induction package or as part of original professional training was suggested. As Becky (occupational therapist) said: "It is something that has to be embedded over time and it's a cultural change and it's about making sure that the staff who have received the training have ongoing support and supervision".

Staff turnover during the project was high, a challenge to maintaining the approach, as explained by Rose (manager):

You're constantly getting staff changes. So even with an occupational therapy workforce, that workforce that was down there at the start of training they um, all decided to go overseas together so they we've got a whole workforce there now that only two or three have done that initial training.

Useful sustainability strategies included peer review sessions and champions. As described by Mary (physiotherapist): "Peer review is a great opportunity to actually have somebody come in and peer review the language and interaction you have with individuals. That is incredibly valuable." John (charge nurse) also felt that not just having champions but modifying their role to enable more time to devote to championing would be beneficial: "Having a person who will just focus on Bridges."

Mary went on to explain how the uptake of Bridges will slowly grow: "I was at a local community event and ran into somebody who had been involved with the speech and language therapy group and her perception was that this process was fabulous, amazing and well and truly worth engaging in."

\section{DISCUSSION}

Overall, our integrated data demonstrated the potential acceptability of Bridges to staff in the targeted DHB but identified challenges and limitations to adopting the approach. The key outcome was a raised awareness across the DHB of the concept of self-management support. Although many staff valued and, at least at a superficial level, bought into the philosophies of Bridges, exhibiting both coherence and cognitive participation, changing actual clinical practice appeared difficult - findings like those reported by Jones and Bailey (2013). Bridges' philosophies, such as shared decision-making, and empowering the patient to lead their own recovery and rehabilitation, were said by our participants to be different to that of the long-engrained medical model of care, where health professionals are viewed by themselves, the patients and the public as the experts, and thus the people to make all decisions. This long-embedded way of practice, in which many staff had been trained, was considered deeply rooted and a place of comfort to work from in times of stress or busyness. As reported by others, whilst rhetoric around therapeutic relationships and person-centred care is cognitively engaging, in the practical context this often disintegrates into inadvertent fostering of dependency and undervaluing of patient personhood (Ahmad et al., 2014; Clark et al., 2018; Eaton et al., 2015; Satink et al., 2015).

Whilst staff in our study verbally espoused the value of Bridges, this did not seem to translate into active engagement in training and learning support. The support provided between workshops by the trainers was minimally utilised, and attendance at followup training was not prioritised by staff, with only $23 \%$ of the staff who were initially trained attending. Possible reasons for low attendance at the follow-up workshop included significant staff turnover as well as movement of key staff and potential champions into different roles during the intervening weeks.

A further possible reason for poor engagement was what workshop participants referred to as a "resistance to change", a known phenomenon within healthcare and one which is complex and multifactorial (Landaeta et al., 2008). Changing health professional practice behaviour is difficult and requires consistent messaging, training, support, and modifying peer group interactions as well as consistent management expectations and support (Johnson \& May, 2015; Levack et al., 2011; Mudge et al., 2015; Norris \& Kilbride, 2014). Johnson and May (2015) hypothesise that successful behaviour change interventions may be those that emphasise both the coherence of (making sense of) the intervention and how the actual response to this (collective action) is measured up to the expectations of external observers or project owners (reflexive monitoring). Behaviour change requires modifications to organisational structure and purposive monitored action, and not just a change in staff beliefs and intentions. In our study, although we gave much attention upfront to coherence and cognitive participation, we possibly did not give enough attention later to collective action and reflexive monitoring. However, our findings are no different to other studies attempting to implement self-management programmes into 
practice (Kennedy et al., 2013, 2014; Sunaert et al., 2011). For example, a trial undertaken in UK general practices reported strong managerial support, and relevant and acceptable training strategies but "failed" at implementing the intervention into routine practice (Kennedy et al., 2013, 2014).

For our Bridges trainers, providing learning support for staff was challenging. Various strategies were adopted to support staff between the two training workshops, but without consistent managerial expectations that these initiatives be utilised, there was limited engagement. The most successful strategy was having local champions exemplified by two senior staff on the AT\&R ward, who facilitated multiple ways of embedding Bridges into practice (emphasising collective action). Further, staff, especially social workers and occupational therapists, who said "we work this way already", were able to be role models in the training workshops, replicating findings of Jones and Bailey (2013).

Consensus from consultation with management was to focus on stroke and train all staff involved in the stroke care pathway. This may have been the wrong decision. Whole team training is advocated, as inter-professional exchanges can facilitate a shared understanding of self-management support (Jones et al., 2017; Kulnick et al., 2016; Jones \& Bailey, 2013), but it is a large undertaking, requiring multiple workshops. Furthermore, as a relatively small DHB, whilst many staff work with stroke survivors, these interactions may be infrequent for some due to the relatively low numbers of stroke survivors seen by the service. Thus, some staff questioned the relevance of the training to their usual work and had few opportunities to use Bridges in practice, at least with stroke survivors. The philosophy and principles of Bridges are applicable to people living with any long-term condition, and the development of Bridges has been applied across different healthcare settings (Kulnik et al., 2016). We acknowledge that a more general approach, inclusive of all patients with complex long-term conditions, would have increased the relevance of Bridges for more staff, especially as the DHB is too small to have specialist services in any one condition, thereby enhancing coherence, cognitive participation, and collective action.

Retrospectively, we should have focused training in only one clinical area, such as AT\&R, and with experience of success in one area, possibly permeating to other areas (improving coherence and reflexive monitoring). Previous studies have found that teams which successfully integrate Bridges into their working practices appear to have a flat hierarchical structure (Jones et al., 2015; Mäkelä et al., 2014, 2019), which is thought to create a more open and supportive environment, enabling more innovative ways of working. The AT\&R team at the DHB appeared to represent this sort of environment, whereas the community-based teams appeared less connected.

Barriers perceived by study participants to their implementation of Bridges included taking too much time; difficulty for use with patients with severe physical, cognitive or communication impairments; reduced staff confidence; and, possibly, too much focus on the Bridges workbook.
Taking too much time was a theme reiterated across all data collected, and indeed, reported by many studies evaluating Bridges (Kulnik et al., 2016; Jones \& Bailey, 2013; Mäkelä et al., 2014, 2019; McKenna, Martin, et al., 2015; Satink et al., 2015) and other self-management programmes (Ahmad et al., 2014; Ross et al., 2019). Following training, it may initially take time and effort to consciously apply self-management support, as it requires health professionals to work in a different way until it becomes a natural part of practice. However, once selfmanagement principles are embedded routinely into everyday patient interactions, it should be more time efficient (Jones \& Bailey, 2013).

The perception that Bridges would be challenging to implement if patients had severe physical, cognitive or communication impairments aligns with other studies (Mäkelä et al., 2014, 2019; McKenna, Martin, et al., 2015; Satink et al., 2015). In our study, however, there was a successful example of a speech and language therapist using Bridges in her aphasia community group. She incorporated several strategies into the group, including facilitated goal setting, joint reflection (within the group), peer support, and enhancement of self-efficacy via vicarious experience (group members telling of their successes). Previous studies support the inclusion and benefits of stroke survivors with cognitive and communication dysfunction in selfmanagement programmes (Cadilhac et al., 2016; Nichol et al., 2019).

Building confidence for all staff, irrespective of their level of professional experience, to use Bridges was noted in our data. For example, junior staff may not be confident using Bridges if the patient's goals appeared at odds with ward protocols or safety standards. A collective team approach is required so that senior staff can support junior staff in the application of Bridges.

For some, the workbook became the focus of the intervention, despite highlighting in training that it was only an assistive tool. Some staff provided the book alone to patients without the accompanying interactive support to develop the patient's selfmanagement skills. Reliance on tools, such as workbooks, rather than on skilled clinical encounters, has been highlighted as an issue in previous self-management support and shared decisionmaking studies (Légaré \& Thompson-Leduc, 2014; Mäkelä et al., 2019). In current training, the Bridges workbook is now only introduced in the second training workshop, not the first.

Suggested strategies to sustain Bridges within the service were (a) the training of new staff and regular refresher workshops for those already trained; (b) having multiple available sources of training, such as online packages; (c) peer review or peer support; and (d) champions. These findings reflect those of previous studies (Jones \& Bailey, 2013; Mäkelä et al., 2014, 2019). The champions were possibly the key factor, and these staff have subsequently been provided with more support, mostly notably time and resources to train other staff.

A limitation of our project was the low engagement of staff in its evaluation component. We endeavoured to collect data via in-depth interviews, but perhaps these were perceived too onerous and time consuming, or possibly a little intimidating. 
In future, alternative methods of collecting data could be considered, such as short online surveys, brief informal interviews, participant diaries, or attending and recording discussions in team meetings. Another approach would be to use an action participatory approach to enable staff to suggest how they would prefer data to be collected (Loewenson et al., 2014). Although engagement in the in-depth interviews was low, the interview findings were congruent and supportive of the data collected from other data sources.

Our learnings from this project, which will guide our future research into the implementation of Bridges in New Zealand, were:

1. Implementing a new intervention takes time and requires sustained support.

2. Start by training a smaller, contained inter-professional team.

3. Senior managers and those with influence need to consistently communicate to staff their expectations and value of the intervention.

4. Identify early adopters and champions of the approach, and ensure they get concentrated training, resources, and managerial support.

5. Whilst acknowledging the importance of and maintaining our input into coherence and cognitive participation, in future we would attend far more to collective action and reflexive monitoring. On reflection of the difficulty of changing practice, future research in self-management training should also focus on entry level health professional training.

\section{CONCLUSION}

We found Bridges to be conceptually acceptable and contextually appropriate in a small New Zealand DHB, and our implementation of the approach raised awareness of selfmanagement support across the service. Changing clinical practice takes time, and staff need to not only develop their knowledge in the area of supporting patient self-management, but they also need to build their own skills and self-efficacy to do this. These processes require managerial support, endorsement, and resources. The learnings from this study can inform future implementation of self-management support programmes for people with long-term conditions.

\section{KEY POINTS}

1. The Bridges stroke self-management approach was found to be contextually appropriative and acceptable to a New Zealand stroke service.

2. Health professionals need time and opportunity to develop knowledge, skills, and self-efficacy to support patient selfmanagement.

3. Changing clinical practice requires managerial value, encouragement, and sustained support.

\section{DISCLOSURES}

Funding for this research was received from the Physiotherapy New Zealand Scholarship Trust Fund. There are no conflicts of interest which may be perceived to interfere with or bias this study.

\section{PERIMISSIONS}

Ethics approval was obtained from the Health and Disability Ethics Committee, New Zealand (reference 18/STH/93).

\section{ACKNOWLEDGEMENTS}

The authors wish to acknowledge the staff of the stroke service involved in this study, Bridges associate trainer Sue Newman, and the contributions made to the study design by Professor Denise Taylor, Professor William Levack, Dr Lynne Clay, and Carina Ziller.

\section{ADDRESS FOR CORRESPONDENCE}

Professor Leigh Hale, School of Physiotherapy, University of Otago, Dunedin, New Zealand.

Email: leigh.hale@otago.ac.nz

\section{REFERENCES}

Ahmad, N., Ellins, J., Krelle, H. \& Lawrie, M. (2014). Person-centred care: From ideas to action. Bringing together the evidence on shared decision making and self-management support. The Health Foundation. https://www.health.org.uk/sites/default/files/ PersonCentredCareFromldeasToAction.pdf

Brown, P. (2009). Economic burden of stroke in New Zealand. In V. L. Feigin (Ed.), Three decades of Auckland Regional Community Stroke (ARCOS) studies: What have we learned and what is next for stroke care and stroke research. (Vol 16, pp. 20-24). AUT University.

Cadilhac, D. A, Kilkenny, M. F., Srikanth, V., Lindley, R. I., Lalor, E., Osborne, R. H., \& Batterbsy, M. (2016). Do cognitive, language, or physical impairments affect participation in a trial of self-management programs for stroke? International Journal of Stroke, 11(1), 77-84. https://doi. org/10.1177/1747493015607522

Clark, E., Bennett, K., Ward, N., \& Jones, F. (2018). One size does not fit all Stroke survivor's views on group self-management interventions. Disability and Rehabilitation, 40(5), 569-576. https://doi.org/10.1080/09638288.20 16.1268653

De Silva, D. (2011). Evidence: Helping people help themselves. Health Foundation. https://www.health.org.uk/sites/default/files/ HelpingPeopleHelpThemselves.pdf

Eaton, S., Roberts, S., \& Turner, B. (2015). Delivering person centred care in long term conditions. BMJ, 350, h181. https://doi.org/10.1136/bmj.h181

Fryer, C. E., Luker, J. A., McDonnell, M. N., \& Hillier, S. L. (2016). Self management programmes for quality of life in people with stroke. Cochrane Database of Systematic Reviews. https://doi. org/10.1002/14651858.CD010442.pub2. CD010442.

Hale, L., Jones, F., Mulligan, H., Levack, W. M. M., Smith, C. M., Claydon, L. S., Milosavljevic, S., Taylor, D., Allan, J., MacKenzie, N., Flannery, J., Edwards, S., Rabone, T., \& Alcock, M. (2014). Developing the Bridges self-management programme for New Zealand stroke survivors: A case study. International Journal of Therapy and Rehabilitation, 21(8), 280-288. https://doi.org/10.12968/ijtr.2014.21.8.381

Hogan, S., \& Siddharth, P. (2018). The social and economic costs of stroke in New Zealand. NZIER report to the Stroke Foundation. New Zealand Institute of Economic Research. https://think-asia.org/bitstream/ handle/11540/8929/social_and_economic_costs_of_stroke_-_report. pdf? sequence $=1$ 
Johnson, M. J., \& May, C. R. (2015). Promoting professional behaviour change in healthcare: What interventions work, and why? A theoryled overview of systematic reviews. BMJ Open, 5, e008592. https://doi. org/10.1136/bmjopen-2015-008592

Jones, F., \& Bailey, N. (2013). How can we train stroke practitioners about patient self-management? Description and evaluation of a pathway wide training programme. European Journal of Person Centred Healthcare, 1(1), 246-254.

Jones, F., \& Brimicombe, L. (2014). Every interaction counts: The 'Bridges' approach to stroke self-management. International Journal of Therapy and Rehabilitation, 21(4), 158-159.

Jones, F., Gage, H., Drummond, A., Bhalla, A., Grant, R., Lennon, S., McKevitt, C., Riazi, A., \& Liston, M. (2015). Feasibility study of an integrated stroke self-management programme: A cluster-randomised controlled trial. BMJ Open, 6(1), e008900. https://doi.org/10.1136/ bmjopen-2015-008900

Jones, F., Mandy, A., \& Partridge, C. (2009). Changing self-efficacy in individuals following a first time stroke: Preliminary study of a novel selfmanagement intervention. Clinical Rehabilitation, 23(6), 522-533. https:// doi.org/10.1177/0269215508101749

Jones, F., McKevitt, C., Riazi, A., \& Liston, M. (2017). How is rehabilitation with and without an integrated self-management approach perceived by UK community-dwelling stroke survivors? A qualitative process evaluation to explore implementation and contextual variations. British Medical Journal Open, 7(4), e014109. https://doi.org/10.1136/ bmjopen-2016-014109

Jones, F., Pöestges, H., \& Brimicombe, L. (2016). Building bridges between healthcare professionals, patients and families: A coproduced and integrated approach to self-management support in stroke. Neurorehabilitation, 39(4), 471-480. https://doi.org/10.3233/NRE-161379

Jones, F. (2006). Strategies to enhance chronic disease self-management: How can we apply this to stroke? Disability and Rehabilitation, 28(13-14), 841-847. https://doi.org/10.1080/09638280500534952

Kennedy, A., Bower, P., Reeves, D., Blakeman, T., Bowen, R., Chew-Graham, C., Eden, M., Fullwood, C., Gaffney, H., Gardner, C., Lee, V., Morris, R., Protheroe, J., Richardson, G., Sanders, C., Swallow, A., Thompson, D., \& Rogers, A.; Salford National Institute for Health Research Gastrointestinal Programme Grant Research Group. (2013). Implementation of self management support for long term conditions in routine primary care settings: Cluster randomised controlled trial. BMJ, 346, f2882. https://doi. org/10.1136/bmj.f2882

Kennedy, A., Rogers, A., Chew-Graham, C., Blakeman, T., Bowen, R., Gardner, C., Lee, V., Morris, R., \& Protheroe, J. (2014). Implementation of a self-management support approach (WISE) across a health system: A process evaluation explaining what did and did not work for organisations, clinicians and patients. Implementation Science 9, 129. https://doi. org/10.1186/s13012-014-0129-5

Kulnik, S. T., Pöestges, H., Brimicombe. L, Hammond, J. \& Jones, F. (2016) Implementing an interprofessional model of self-management support across a community workforce: A mixed methods evaluation study. Journal of Interprofessional Care, 31(1), 75-84. https://doi.org/10.1080/1356182 0.2016 .1246432

Landaeta, R. E., Mun, J. H, Rabadi, G., \& Levin, D. (2008). Identifying sources of resistance to change in healthcare. International Journal of Healthcare Technology and Management, 9 (1), 74-96. https://doi.org/10.1504/ IJHTM.2008.016849

Légaré, F., \& Thompson-Leduc, P. (2014). Twelve myths about shared decision making. Patient Education and Counseling, 96(3), 281-186. https://doi. org/10.1016/j.pec.2014.06.014

Levack, W. M., Dean, S. G., Siegert, R. J., \& McPherson, K. M. (2011). Navigating patient-centered goal setting in inpatient stroke rehabilitation: How clinicians control the process to meet perceived professional responsibilities. Patient Education and Counselling, 85(2), 206-213. https://doi.org/10.1016/j.pec.2011.01.011
Loewenson, R., Laurell, A. C., Hogstedt, C., D’Ambruoso, L., \& Shroff, Z. (2014). Participatory action research in health systems: A methods reader. TARSC, AHPSR, WHO, IDRC Canada. Equinet. https://equinetafrica.org/ sites/default/files/uploads/documents/PAR_Methods_Reader2014_for_web. pdf

Mäkelä, P., Gawned, S., \& Jones, F. (2014). Starting early: Integration of self-management support into an acute stroke service. BMJ Quality Improvement Reports, 3, u202037.w1759. https://doi.org/10.1136/ bmjquality.u202037.w1759

Mäkelä, P., Jones, F., Inês de Sousa de Abreu, M., Hollinshead, L., \& Ling, J. (2019). Supporting self-management after traumatic brain injury: Codesign and evaluation of a new intervention across a trauma pathway. Health Expectations, 22(4), 632-642. https://doi.org/10.1111/hex.12898

McKenna, S., Jones, F., Glenfield, P., \& Lennon, S. (2015). Bridges selfmanagement programme for people in the community: A feasibility randomized controlled trial. International Journal of Stroke, 10(5), 697704. https://doi.org/10.1111/ijs.12195

McKenna, S., Martin, S., Jones, F., Gracey, J. \& Lennon, S. (2015). The Bridges stroke self-management program for stroke survivors in the community: Stroke, carer and health professional participants' perspectives. Physical Medicine and Rehabilitation International, 2(1), 1030-1038.

McKevitt, C., Fudge, N., Redfern, J., Sheldenkar, A., Crichton, S., Rudd, A. R., Forster, A., Young, J., Nazareth, I., Silver, L. E., Rothwell, P. M., \& Wolfe, C. D. A. (2011). Self-reported long-term needs after stroke. Stroke, 42(5), 1398-1403. https://doi.org/10.1161/STROKEAHA.110.598839

Moir, T. (2018). Why is implementation science important for intervention design and evaluation within educational settings? Frontiers in Education, 3, 61. https://doi.org/10.3389/feduc.2018.00061

Mudge, S., Kayes, N., \& McPherson, K. (2015). Who is in control? Clinicians' view on their role in self-management approaches: A qualitative metasynthesis. BMJ Open, 5, e007413. https://doi.org/10.1136/ bmjopen-2014-007413

Murray, E., Treweek, S., Pope, C., MacFarlane, A., Ballini, L., Dowrick, C., Finch, T., Kennedy, A., Mair, F., O’Donnell, C., Ong, B. N., Rapley, T., Rogers, A., \& May, C. (2010). Normalisation process theory: A framework for developing, evaluating and implementing complex interventions. BMC Medicine, 8, 63. https://doi.org/10.1186/1741-7015-8-63

Newbronner, L., Chamberlain, R., Borthwick, M., Baxter, M., \& Sanderson, D. (2013). Sustaining and spreading self-management support: Lessons from Co-creating Health Phase 2. Health Foundation.

Nichol, L., Hill, A. J., Wallace, S. J., Pitt, R., Baker, C., \& Rodriguez, A. D. (2019). Self-management of aphasia: A scoping review. Aphasiology, 33(8), 903-942. https://doi.org/10.1080/02687038.2019.1575065

Norris, M., \& Kilbride, C. (2014). From dictatorship to a reluctant democracy: Stroke therapists talking about self-management. Disability and Rehabilitation, 36(1), 32-38. https://doi.org/10.3109/09638288.2013.77 6645

O'Neill, D., Horgan, F., Hickey, A., \& McGee, H. (2008). Long term outcome of stroke: Stroke is a chronic disease with acute events. BMJ, 336(7642), 461. https://doi.org/10.1136/bmj.39500.434086.1F

Peters, D. H., Adam, T., \& Alonge, O., Agyepong, I. A, \& Tran, N. (2013). Republished research: Implementation research: What it is and how to do it. BMJ, 347, f6753. https://doi.org/10.1136/bmj.f6753

Pindus, D. M., Mullis, R., Lim, L., Wellwood, I., Rundell, A. V., Azah Abd Aziz, N., \& Mant, J. (2018). Stroke survivors' and informal caregivers' experiences of primary care and community healthcare services - A systematic review and meta-ethnography. PLOS ONE, 13(4), e0196185. https://doi.org/10.1371/journal.pone.0196185

Powell, B. J., Fernandez, M. E., Williams, N. J., Aarons, G. A, Beidas, R. S., Lewis, C. C., McHugh, S. M., \& Weiner, B. J. (2019). Enhancing the impact of implementation strategies in healthcare: A research agenda. Front Public Health, 7, 3. https://doi.org/10.3389/fpubh.2019.00003 
Ranta, A. (2018). Projected stroke volumes to provide a 10-year direction for New Zealand stroke Services. New Zealand Medical Journal, 131(1477), $1-14$.

Ross, J., Stevenson, F. A., Dack, C., Pal, K., May, C. R., Michie, S., Yardley, L., \& Murray, E. (2019). Healthcare professionals' views towards self-management and self-management education for people with type 2 diabetes. BMJ Open, 9(7), e029961. https://doi.org/10.1136/ bmjopen-2019-029961

Satink, T., Cup, E. H. C., de Swart, B. J. M., \& Nijhuis-van der Sanden, M. W. $G$ (2015). Self-management: Challenges for allied healthcare professionals in stroke rehabilitation - A focus group study. Disability and Rehabilitation, 37(19), 1745-1752. https://doi.org/10.3109/09638288.2014.976717

Sunaert, P., Vandekerckhove, M., Bastiaens, H., Feyen, L., Vanden Bussche, P., De Maeseneer, J., De Sutter, A., \& Willems, S. (2011). Why do GPS hesitate to refer diabetes patients to a self-management education program: A qualitative study. BMC Family Practice, 12, 94. https://doi. org/10.1186/1471-2296-12-94
Taylor, A., Monsanto, X., Kilgour, H., Smith, C., \& Hale, L. (2019). Attitudes of healthcare professionals towards self-management for patients with stroke. New Zealand Journal of Physiotherapy, 47(1), 25-35. https://doi. org/10.15619/NZJP/47.1.04

The Evidence Centre for National Voices. (2014). Prioritising person-centred care: Supporting self-management. https://www.nationalvoices.org.uk/ sites/default/files/public/publications/supporting_self-management.pdf

Thomas, D.R. (2016). A general inductive approach for analyzing qualitative evaluation data. American Journal of Evaluation, 27(2), 237-246. https:// doi.org/10.1177/1098214005283748

Yin, R. K. (2014). Case study research design and methods (5th ed.). Sage. 